\title{
Growth in Biofuels Markets: Long Term Environmental and Socioeconomic Impacts
}

Over the last several years increasing energy and petroleum prices have propelled biofuels and the feedstocks used to produce them, to the forefront of alternative energy production. This growth has increased the linkages between energy and agricultural markets and these changes around the world are having a significant effect on agricultural markets as biofuels begin to play a more substantial role in meeting the world's energy needs. Biofuels are alternatively seen as a means to reduce carbon emissions, increase energy independence, support rural development and to raise farm income. However, concern has arisen that the new demand for traditional commodities or alternative commodities which compete for land can lead to higher food prices and the environmental effects from expanding crop acreage may result in uncertain changes in carbon emissions as land is converted both in the US and abroad.

While a number of studies examine changes in land use and consumption from changes in biofuels policies many lack effective policy representation or complete coverage of land types which may be diverted in to energy feedstock production. Many of these biofuels and renewable energy induced land use changes are likely to occur in developing countries with at-risk consumers and on environmentally sensitive lands. Our research has improved the well known FAPRI-MU modeling system which represents US agricultural markets and policies in great detail and added a new model of land use and commodity markets for major commodity producers, consumers and trade dependent and food insecure countries as well as a rest of the world aggregate. The international modules include traditional annual crop lands and include perennial crop land, pasture land, forest land and other land uses from which land may be drawn in to biofuels or renewable energy feedstock production. Changes in calorie consumption in food insecure countries from changes in renewable energy policy can also be examined with a calorie module that was developed.

The econometric model development provides an important tool to examine the indirect but important and potentially substantial secondary effects of the use of agricultural land as an input into renewable energy production including changes in greenhouse gas production and calorie consumption. With the expansion of biofuels support and consumption as well as proposals for similar support of biomass electricity the research and tools developed remain at the forefront of renewable energy policy analysis.

\section{Comparison of Accomplishments vs. Project Goals}

Project goal

1) Improvement of current structural models of US agriculture to incorporate domestic biofuels policies and to expand land use representation to include biomass crops thought to have the most potential in the production of second generation biofuels.

2) Create a model of international agricultural markets to determine response in developing countries most at risk from changes in food prices. 
3) Incorporate into the system structure to evaluate the long term impacts of prevailing biofuels policies of the EU and US by simultaneously estimating the global changes in

a. Agricultural commodity prices and trade

b. Resulting changes in land use

c. Welfare impacts on consumers, especially vulnerable groups.

4) Simulate effects under alternative technology pathways or outcomes for the production of biofuels

5) Examine the effects of biofuels production and polices on commodity price volatility

The project goal was to establish a system to evaluate the long term impacts of prevailing biofuel policies of the EU and US by simultaneously estimating the global changes in prices, trade, land use and welfare impacts on consumers, especially vulnerable groups.

The project was originally envisioned to simulate changes in biofuel technology. In support of this and complimentary research objectives, models of biomass crop production, corn stover and swtichgrass for example, were developed and analysis conducted around alternative policy implementation and technology paths both in the production of cellulosic ethanol from these feedstocks as well as in other biofuels production patheways. The international land use model was also used for analysis of the resulting land use changes from alternative US policies and those results disseminated through publications and conference proceedings. The systems developed continue to be used in the submission of a publication which examines the resulting change in food consumption in the developing world in support of the projects original objectives.

As proposed, this project has ultimately resulted in the publication of research articles in scholarly journals directly and closely related to the objectives outlined in the original proposal. The research has resulted in modeling resources which will be of continued importance in the debate on the costs and benefits of the use of agricultural commodities in the production of renewable energy.

The primary employment of FAPRI models is to provide the US Congress with tailored research on considered policy choices. The advancement of existing FAPRI models to more accurately incorporate biofuels has added to the support of policy decision making in a very direct way. The development of the international model components has added significantly to the ability to examine indirect land use change in the rest of the world from changes in domestic biofuels policy. The last two years have only heightened the importance of the research topic.

The effect of biofuels production and policies on commodity price volatility were addressed by taking the model improvements implemented in the FAPRI-MU modeling system used for annual congressional baseline process and incorporating them into the FAPRI-MU stochastic system where the policies could be examined over a wide range of uncertainties which contribute to movements in commodity prices such as crop yields and petroleum prices. The model incorporates the expanded connection between agricultural commodities and energy markets and explores the non-linearities in US biofuels polices that could alter demand response. The result is 
the first examination of its kind to quantify the effects of US biofuels policies on commodity price volatility and was published as a chapter in the Handbook of Bioenergy Economics and Policy.

Meyer, Seth and Wyatt Thompson. "Demand and Commodity Price Behavior Under Evolving Biofuel Markets and Policies." forthcoming Book chapter in Handbook of Bioenergy Economics and Policy. Madhu Khanna, Jurgen Scheffran, and David Zilberman (editors). Springer-Verlag.

The tools and expertise developed are at the forefront of biofuel policy analysis and has generated a method which can be applied to other renewable energy sectors which interact with the agricultural sector over land.

\section{Timeline and Summarization of Project Activities}

The project was conducted over the period 9/1/2007 to 8/31/2010 and publications based on the work have continued to be submitted and some are awaiting decisions at the time of this final report.

The last quarter of 2007 was used to evaluate international modeling platforms that could be used as a basis for the international agricultural markets model outlined in the original proposal. Several modeling systems were examined, and the FAPRI-ISU international models were heavily investigated. While the country and commodity coverage in this system was good, the model is limited to primarily annual crop lands at the exclusion of pasture, forestry and other land uses including some perennial crops. In addition, the cross prices used to determine acreage is limited in part due to the way the models are divided among analysts. The GTAP model was also examined with respect to its land allocation system.

New biofuels legislation, the Energy Independence and Security Act of 2007 (EISA), was also passed during this period and initial efforts were made to incorporate and analyze the quantitative mandates imposed in this legislation. The approach was an abstraction and limited to first generation biofuels, but at the time, actual policy implementation was uncertain.

In the first two quarters of 2008 it was determined that the existing FAPRI-ISU international models were an insufficient basis to start from to meet the grant objectives and the gathering of the needed international data on agricultural commodities and land use began in earnest. In the US model, additional details on implementation of EISA were gathered and a detailed representation of renewable identification number markets was incorporated with the exception of cellulosic biofuels and biomass crops. This was the first model of its type in existence which incorporated the market for the policy obligations in renewable fuels.

In the third and fourth quarters of 2008 and into the first two quarters of 2009 a new international land use and agricultural markets model was constructed. Simultaneously, preliminary specifications for biomass crops in the US deterministic and stochastic model were laid out and tested. Calorie data were gathered to pair with the international model components. The models were used for preliminary examination of Brazilian response to domestic US biofuels policies 
In the second half of 2009 the EISA representation was completed for cellulosic biofuels and incorporated into the FAPRI annual baseline process. At the same time, second generation cellulosic biofuels were incorporated into the EISA compliance mechanism. A simple calorie model for the developing countries was created and validated.

In 2010, several scenarios which examine the effects of fully enforcing the cellulosic biofuel mandate under EISA were run and the effect of technology paths on the costs to commodity and biofuel consumers and taxpayers were examined. The results of these studies have been published or have been submitted for publication. The international model was also used to examine international land use effects and agricultural commodity consumption quantities in the developing country aggregates and at least one additional publication on consumption is in the review process. Model improvement and expansion of abilities in the area of calorie consumption have continued beyond the end of the grant period. The issue remains one of great importance and the research funded by this grant has positioned the research institutes involed to address these questions as new policies and technologies emerge and provide to policy makers additional resources to consider the impacts of decisions on consumers at home and abroad.

\section{Identify Developed Products}

\section{Biomass and Biofuel Representation in the FAPRI-MU Structural Policy Model}

The deterministic and stochastic models which are widely used at FAPRI-MU were expanded to include additional detail for the production and consumption of $1^{\text {st }}$ and $2^{\text {nd }}$ generation biofuels. Improvements were made to the models supply side where the agricultural crops used for the production of biofuels, such as corn and soybean oil, were already incorporated. Additional detail to the supply side was added to incorporate technologies which were in place and growing. For section generation biofuels such as cellulosic ethanol or biodiesel, which are not produced in any quantities today, the market was created from a meta-analysis of research on current and anticipated future costs for production, transport and processing of the biomass feedstocks. The model is unique in its representation of these crops within existing crop systems as well as the detail of the policy representation which is driving growth in this sector. To our knowledge, no other model which can incorporate these effects exist today. The model structure is documented in the following publication.

Meyer, Seth and Wyatt Thompson. "FAPRI-MU US Biofuels, Corn Processing, Distillers Grains, Fats, Switchgrass, and Corn Stover Model Documentation-MU Report 09-10, FAPRI, University of Missouri, Columbia, September 2010.

\section{International Agricultural and Land Use Model}

The scope of the model in terms of commodities and countries is as follows

Commodities: wheat, rice, corn, other grains, soybeans, rapeseed, sunflower, oilseed oils, oilseed meals, palm oil, sugar, beef, pork and poultry. 
Countries: Argentina, Brazil, Canada, China, the European Union, India, Indonesia, Japan, Malaysia, Mexico, the United States and four developing country aggregates based on calorie consumption and trade dependence, the remainder of the world is represented through reduced form trade equations.

The United States agriculture sector is represented by the FAPRI-MU stochastic model.

Developing country aggregates are chosen to simulate how shocks induced by biofuels and renewable energy policy in developed countries are transmitted into developing countries and if such shocks imperil food security. Developing country groupings are based on average calorie consumption and dependence on trade, with four groupings of high or low relative values for each.

Land within the international model is allocated in a set of nested branches. Land is first divided between forest and agricultural uses and other land uses. Agriculture land is then separated from forestry land and then further divided into annual crops, perennial crops, palm, sugar and pasture land. Annual crops are then further divided into the crop commodities above. Land allocation at each stage depends on the relative prices of land use alternatives. Supply and demand for each of the agricultural commodities are disaggregated into food, feed, stockholding and other categories and are determined by world clearing commodity prices transmitted into local markets.

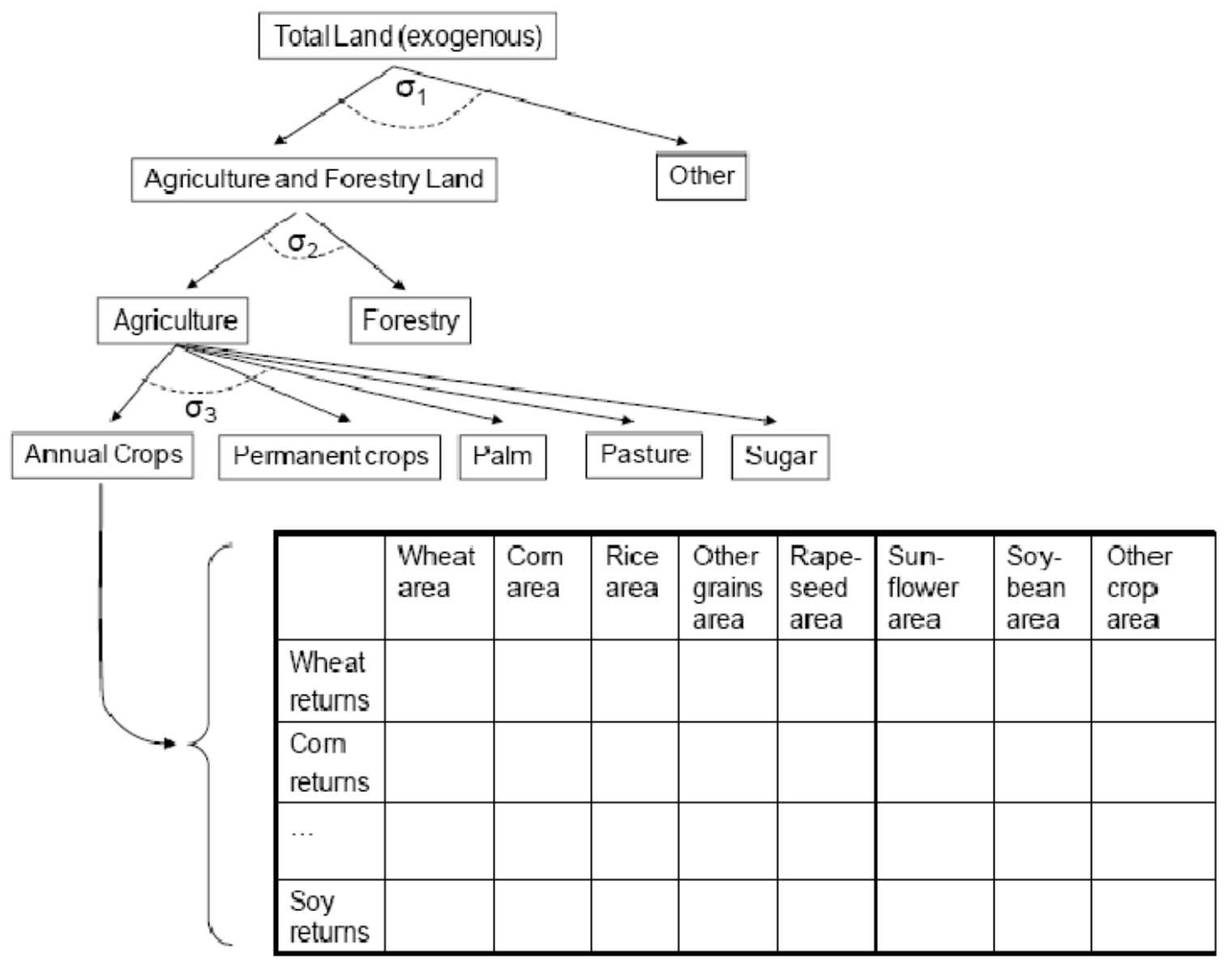


The model structure and its use can be seen in the following journal article.

Thompson, Wyatt. "Biofuel Effects on Markets and Indirect Effects on Land Use and Food." Journal of International Agricultural Trade and Development 6 (1): 117-132. 2010.

\section{Journal Articles/Conference Proceedings/Publications}

The tools and expertise developed under this grant have directly and indirectly contributed to a large number of publications to advance the understanding of the socioeconomic impacts of biofuel production and policies and to inform policy makers of the implications of their decision making process. The publications target a wide audience from peers in the academic community to policy makers in Washington D.C. and the participants in this research are looked upon by both groups as experts in the area of biofuel policy and socioeconomic and market implications.

\section{Refereed Articles}

Ziolkowska, Jadwiga, William Meyers, Seth Meyer and Julian Binfield. "Targets and mandates: lesson learned from EU and US biofuel enforcement mechanisms.” AgBioForum. Accepted

Thompson, Wyatt, Seth Meyer, and Pat Westhoff. "The New Markets for Renewable Identification Numbers.” Applied Economic Perspectives and Policy. In press.

Thompson, Wyatt, Seth Meyer, and Travis Green. "The U.S. Biodiesel Use Mandate and Biodiesel Feedstock Markets.” Biomass and Bioenergy, Vol. 34 (6), pp 883-889, June 2010.

Furuya, J., S. Kobayashi, and S.D. Meyer. "Impacts of Global Warming on the World Food Market According to SRES Scenarios.” Proceedings of the International Conference on Climate Change and Global Warming, World Academy of Science, Engineering and Technology, Vol. 45 September 2009.

Thompson, Wyatt, Seth Meyer and Patrick Westhoff. "Renewable Identification Numbers are the tracking Instrument and Bellwether of US Biofuel Mandates.” EuroChoices, Vol. 8 (3), pp 43-50, June 2009.

Thompson, Wyatt and Seth Meyer. "Simulated ethanol transportation patterns and costs." Journal of the Transportation Research Forum, Vol. 48 (1), Spring 2009.

Thompson, Wyatt, Seth Meyer, Nicholas Kalaitzandonakes and James Kaufman. "Ethanol Policy Changes to Ease Pressures in Corn Markets: Could they Work?” Choices, Vol. 24 (1), pp 40-44, 2009.

Thompson, Wyatt, Seth Meyer and Patrick Westhoff."How Does Petroleum Price and Corn Yield Volatility Affect Ethanol Markets with and without an Ethanol Use Mandate?” Energy Policy, Vol. 37(2), pp 745 - 749, February 2009. 


\section{Invited Journal Articles}

Whistance, Jarrett, Wyatt Thompson, and Seth Meyer. "Ethanol Policy Effects on US Natural Gas Prices and Quantities." American Economic Review, Vol 100 (2) pp 178-82, May 2010

Thompson, Wyatt, Seth Meyer, and Pat Westhoff. "What to Conclude about Biofuel Mandates from

Evolving Prices for Renewable Identification Numbers?” Invited paper to be published in the proceedings issue of the American Journal of Agricultural Economics in 2010.

Thompson, Wyatt. "Biofuel Effects on Markets and Indirect Effects on Land Use and Food.” Journal of International Agricultural Trade and Development 6 (1): 117-132. 2010.

Meyer, Seth, Julian Binfield and Patrick Westhoff. "Interactions Between Energy Markets and Agriculture in the US: A Stochastic Approach.” Journal of International Agricultural Trade and Development, Vol 6 (1) pp 21-44, 2010.

Meyer, Seth. "The Impact of the Ethanol Boom on Rural America: Commentary,” Regional Economic Development, Federal Reserve Bank of St. Louis, Vol. 5 (1), pp 74-77, April 2009. Invited Paper.

Kalaitzandonakes, Nicholas, James Kaufman, Seth Meyer and Wyatt Thompson. "Long-Term Sustainability in the U.S. Corn Ethanol Industry: Some Key Determinants: Panel Discussion,” Regional Economic Development, Federal Reserve Bank of St. Louis, Vol. 5 (1), pp 103-115, April 2009. Invited Paper.

\section{Articles in Review}

Meyer, Seth, Julian Binfield and Patrick Westhoff. “Technology adoption under U.S. biofuel policy: Do producers or consumers benefit?” European Review of Agricultural Economics. Revised and resubmitted.

Thompson, Wyatt, Jarrett Whistance and Seth Meyer. "Effects of US biofuel policies on US and world petroleum product markets with consequences for greenhouse gas emissions” Energy Policy. In review.

\section{Proceedings, Presentations and Meeting Papers}

Ziolkowska, Jadwiga, William Meyers and Seth Meyer. "Targets and mandates: lessons learned from EU and US biofuel enforcement mechanisms." Proceedings of the International Consortium on Agricultural Biotechnology Research, Ravello, Italy, June 16-18, 2010. 
Meyer, Seth. “Biofuels outlook” Breimyer Seminar, University of Missouri, Columbia, Missouri, May 27 2010. Invited Presentation.

Meyer, Seth. “How energy markets affect crop price volatility” World Outlook Conference, JIRCAS, Tsukuba, Japan, May 27, 2010. Invited Presentation.

Thompson, Wyatt, Seth Meyer, and Pat Westhoff. "What to Conclude about Biofuel Mandates from Evolving Prices for Renewable Identification Numbers?” Invited paper at the annual meeting of the AAEA, Denver, Colorado. Forthcoming in 2010.

Meyer, Seth, Julian Binfield and Patrick Westhoff. "Making the Market: How US Policy Influences Near Term Biofuel Industry Production and Profitability under Technology Adoption.” Selected paper to be presented at the $114^{\text {th }}$ meeting of the European Association of Agricultural Economists, Berlin Germany, April 15-16, 2010.

Donahue, D.K., Seth Meyer and Wyatt Thompson. "RIN Risks: Using Supply and Demand Behavior to Assess Risk in the Markets for Renewable Identification Numbers Used for Renewable Fuel Standard Compliance.” Proceedings of the NCCC-134 Committee on Applied Commodity Price Analysis, Forecasting, and Market Risk Management, April 19-20, 2010.

Thompson, Wyatt, Seth Meyer, and Pat Westhoff. “US Biofuel Policy Effects on Agricultural Commodity Exports” presented at Economics of Alternative Energy Sources and Globalization: The Road Ahead. Orlando, Florida, November 15-17, 2009.

Meyer, Seth. "Biofuels Markets and the Challenges of Cellulosic Ethanol” presented at RINworld Summit, RINSTAR, Dallas, Texas, November 5, 2009.

Meyer, Seth and Julian Binfield. "Interactions between energy markets and agriculture in the US: A stochastic approach." $27^{\text {th }}$ Conference of the IAAE, International Association of Agricultural Economists, Beijing, China, August 16-22 2009. Selected Mini-Symposium: The FAPRI modeling process.

Meyer, Seth. "Biofuel policies and markets in an uncertain world.” MU Energy Summit. University of Missouri, Columbia, MO, April 5, 2009, Selected Presentation.

Meyer, Seth. "Context dependent trade effects of U.S. biofuel policies.” Transition to a Bioeconomy: Global issues in the bioeconomy. Farm Foundation/USDA Conference, Washington, D.C., March 30-31, 2009, Selected Presentation

Meyers, William H. and Seth Meyer. "Causes and Implications of the Food Price Surge” Background paper for the United Nations World Economic Situation and prospects 2009. Department of Economic and Social Affairs, United Nations, New York, December 2008. 51pp.

Kalaitzandonakes, Nicholas, James Kaufman, Seth Meyer and Wyatt Thompson. “Technologies for Biofuel Production and Relevant Impacts”. Invited Paper for conference: Economics of Ethanol: Costs, Benefits and Future Prospects of Biofuels. Federal Reserve Bank, 
Washington University, Weidenbaum Center on the Economy, Government and Public Policy, International Center for Advanced Renewable Energy and Sustainability. Saint Louis, Missouri, November 14, 2008.

Meyer, Seth. "Ethanol outlook and uncertainty, a response" invited presentation: Economics of Ethanol: Costs, Benefits and Future Prospects of Biofuels. Federal Reserve Bank, Washington University, Weidenbaum Center on the Economy, Government and Public Policy, International Center for Advanced Renewable Energy and Sustainability. Saint Louis, Missouri, November 14, 2008.

Meyer, Seth. "Development in Agricultural Prices, Policies and Petroleum" invited presentation, "The Immoral Biofuel”, Royal Academy of Forestry and Agriculture, Stockholm Sweden. October 23, 2008.

Thompson, Wyatt, Seth Meyer and Patrick Westhoff. "Potential for uncertainty about indirect effects of ethanol on land use in the case of Brazil.” In M. Khanna (ed.) Transition to a Bioeconomy: Environmental and Rural Development Impacts. Proceedings of Farm Foundation/USDA Conference, Saint Louis, Missouri, October 15-16, 2008, Farm Foundation, Oak Brook, Illinois, 2009.

Kalaitzandonakes, Nicholas, James Kaufman, Seth Meyer, and Wyatt Thompson. "The Impact of Biotech Corn Traits on Ethanol Production.” In M. Khanna (ed.) Transition to a Bioeconomy: Environmental and Rural Development Impacts. Proceedings of Farm Foundation/USDA Conference, Saint Louis, Missouri, October 15-16, 2008, Farm Foundation, Oak Brook, Illinois, 2009.

Meyer, Seth. "Biofuels Policy and Outlook" invited presentation, "Growing the Bioeconomy", Iowa State University, Ames, Iowa., September 9, 2008.

Meyer, Seth, Wyatt Thompson and Pat Westhoff. In panel, "Sustainable Biorefining Systems, Preliminary Findings from the NC506 Project." Annual meetings of the American Agricultural Economics Association, Orlando, Florida.,July 29, 2008.

Meyer, Seth. "Distillers grains: the DG market and its relationship to corn”, presentation, Annual meetings of the American Agricultural Economics Association, Orlando, Florida. July 28, 2008.

Thompson, Wyatt, Seth Meyer and Patrick Westhoff. "Policy risk for the biofuels industry.” In B. English (ed.) Risk, Infrastructure, and Industry Evolution, Proceedings of Farm Foundation/USDA Conference, Berkeley, California, June 24-25, 2008, Farm Foundation, Oak Brook, Illinois, January 2009.

Meyer, Seth. "Policy risk: Potential consequences for the biofuels industry", presentation, Farm Foundation: Risk, Infrastructure, and Industry Evolution. Berkeley California., June 24, 2008 
Meyer, Seth. "Transient and persistent factors in commodity demand", invited presentation, Twenty-FirstCentury Systems Agriculture Committee, the National Academies, Kansas City Missouri, March 27, 2008.

Meyer, Seth and Wyatt Thompson. "Ethanol: demand characteristics and spatial disposition”, invitedpresentation, Annual Meetings of the Transportation Research Forum, Dallas Texas, March 17-19, 2008.

Meyer, Seth and William H. Meyers. "US Biofuels Analysis under Uncertainty: Volatility in the BiofuelsIndustry and Effects on Commodity Prices." In Joe L. Outlaw, James A. Duffield, David P. Ernstes (eds.) Biofuels, Food \& Feed Tradeoffs. Oak Brook, Illinois: Farm Foundation, 2008.

Meyer, Seth. "Outlook for U.S. Biofuels" presentation to the Policy Research Institute in the Ministry of Agriculture Fisheries and Forestry, Tokyo, Japan, November 21, 2007.

\section{Other Publications}

Meyer, Seth and Wyatt Thompson. "FAPRI-MU US Biofuels, Corn Processing, Distillers Grains, Fats, Switchgrass, and Corn Stover Model Documentation-MU Report 09-10, FAPRI, University of Missouri, Columbia, September 2010.

Meyer, Seth and Wyatt Thompson. "US Biofuel Briefing Book” FAPRI-MU Report 04-10, FAPRI, University of Missouri, Columbia, June 2010.

Food and Agricultural Policy Research Institute. “Model of the US Ethanol Market” FAPRI-MU Report 01-10, FAPRI, University of Missouri, Columbia, March 2010

Kaufman, James, Wyatt Thompson, and Seth Meyer. "Implications of the Low Carbon Fuel Standard for State and National Ethanol Use." University of Missouri, Department of Agricultural Economics Working Paper No. AEWP 2009-05, August 2009.

Thompson, Wyatt, Seth Meyer and Patrick Westhoff. "Renewable Identification Number Markets: Draft baseline table” FAPRI-MU Report 07-09, FAPRI, University of Missouri, Columbia, September 2009.

Meyer, Seth, Patrick Westhoff and Wyatt Thompson. "Impacts of selected US ethanol policy options” FAPRI-MU Report 04-09, FAPRI, University of Missouri, Columbia, May 2009.

Food and Agricultural Policy Research Institute. "State Support for Ethanol Use and State Demand for Ethanol Produced in the Midwest” FAPRI-MU Report 11-08, FAPRI, University of Missouri, Columbia, November 2008.

Food and Agricultural Policy Research Institute. "Model of the US Ethanol Market” FAPRI-MU Report 07-08, FAPRI, University of Missouri, Columbia, July 2008. 
Food and Agricultural Policy Research Institute. "Biofuels: Impact of Selected Farm Bill Provisions and other Biofuel Policy Options” FAPRI-MU Report 06-08, FAPRI, University of Missouri, Columbia, June 2008.

Food and Agricultural Policy Research Institute. "The Energy Independence and Security Act of 2007” FAPRI-MU Report 01-08, FAPRI, University of Missouri, Columbia, January 2008. 